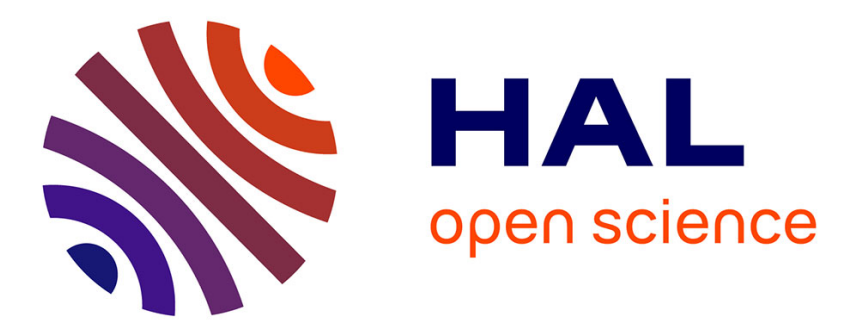

\title{
Placing Subway Signs: Practical Properties of Signs at Work
}

\author{
Jérôme Denis, David Pontille
}

\section{To cite this version:}

Jérôme Denis, David Pontille. Placing Subway Signs: Practical Properties of Signs at Work. Visual Communication, 2010, 9 (4), pp.441-462. halshs-00551242

\section{HAL Id: halshs-00551242 \\ https://shs.hal.science/halshs-00551242}

Submitted on 3 Jan 2011

HAL is a multi-disciplinary open access archive for the deposit and dissemination of scientific research documents, whether they are published or not. The documents may come from teaching and research institutions in France or abroad, or from public or private research centers.
L'archive ouverte pluridisciplinaire HAL, est destinée au dépôt et à la diffusion de documents scientifiques de niveau recherche, publiés ou non, émanant des établissements d'enseignement et de recherche français ou étrangers, des laboratoires publics ou privés. 


\title{
Placing Subway Signs: Practical Properties of Signs at Work
}

\author{
Jérôme DENIS \\ LTCI (UMR5141) CNRS - Telecom ParisTech \\ Département Sciences Économiques et Sociales \\ jerome.denis@telecom-paristech.fr
}

David PONTILLE

IIAC - CNRS (UMR 8177) / EHESS (LC 12)

Équipe «Anthropologie de l'écriture »

pontille@ehess.fr

\begin{abstract}
This article complements previous studies stressing the importance of the emplacement of signs in public spaces by focusing on the placement process itself. The authors' ethnographic study of the Paris subway shows that the way-finding system operates in a process of graphical ordering within which the standardized shape, content and emplacement of each sign are crucial. However, the placement work does not simply consist of following instructions. The authors show that, in order to find the proper place for boards, stickers and posters, workers have to explore the environment and reconcile the sign placement policy with the ecology of the local sites. In doing so, workers do not just discover an emplacement designated for a particular sign but enact an available place, mobilizing numerous embodied practices. During this process, signs themselves are not treated as stabilized entities; they oscillate between what the authors term 'practical properties' that arise from the combination of objects, bodies and environment.
\end{abstract}

\section{Keywords}

Ecology $・$ Ethnography $\cdot$ Placement Work $\cdot$ Pragmatics $\cdot$ Subway Signs

Denis, J. and Pontille, D. 2010. Placing Subway Signs:Practical Properties of Signs at Work Visual Communication, 9 (4), p. 441-462. 


\section{Introduction}

Various studies have shown that the understanding of our 'visual culture' (Jenks, 1995; Van Leeuwen and Jewitt, 2001) and the role of signs in our world raise the question of the relationships that signs have with their surroundings. This issue highlights a particular semiotic property: emplacement. We summarize three recent approaches to illustrate the interest of such a focus.

As an epigraphist, Petrucci (1993) reconstructs the history of 'public lettering' and traces its social functions from the 11th century through to the modern period. He notably sheds light on the relations between the functions and styles of letters and their location of appearance. Public lettering is here described as an instrument of public power: dominant groups managed the emplacement of inscriptions in urban spaces, such as monuments, façades or central squares, to enhance their visibility. From this perspective, public lettering and their locations are part of a programme: they perform a political public space.

From a semiotic standpoint, Scollon and Scollon (2003) make a plea for studying 'signs in place'. They suggest investigating the issue of indexicality (relationships that signs have with their surroundings) with the concept of 'emplacement'. They advocate a 'geosemiotics' that offers many resources for deviating from traditional semiotics that generally interprets isolated signs. The main idea is that signs fully acquire their meaning only from the place they occupy in a particular setting.

Finally, from an actor-network perspective, Latour and Hermant (1998: 27-35) explore the invisible infrastructures that support Paris as a city. They show that street name plates have to be at a 'proper' place, which they analyse as the outcome of a large network of inscriptions and administrative departments. Here, sign emplacement is the result of the alignment of heterogeneous elements, each raising political, moral and technical issues. The sign in place is therefore an element of a broad assemblage of devices that perform the city.

Even though these studies vary in their approaches and objects, they all emphasize the place of signs as a crucial condition of felicity but hardly tackle the placement process. Petrucci (1993) studies designers and typographs but gives very little attention to the workers who engrave, stick bills or put public inscriptions in place. Focusing on indexicality, Scollon and Scollon (2003) mention that indications on a board are useless when the sign is still in the hands of its manufacturer, but do not study the activities of those involved in its installation. Finally, Latour and Hermant (1998: 27-35) are less interested in the placement process itself than in the stream of successive transformations in which a sign goes from one city department to another, one map to one delivery slip, one plate to one street.

Yet, in order to be in place, signs have to be put in a particular site, and this operation remains largely undocumented. The placement of signs is a full-time activity that requires specific operations, skills and know-how. These operations play a great part in the setting of visual environments. We think that an analysis of such operations, through an ethnographic study of placement, is useful for understanding signs and visual communication from a pragmatic point of view: neither per se, nor by observing their uses, but by questioning the practical conditions of their configuration. 
From this perspective, we assume that the 'proper' place is neither a potentiality inscribed in the sign, nor an available spot ready to be filled within the environment. Environmental properties of public inscriptions are supposed to be literally highlighted. Beyond the sole problem of indexicality, it is the practical abilities of signs that are at stake in the installation process. Therefore, semiotic features are never taken for granted during the course of placement in workers' operations. We will show that placement work requires signs to be treated in heterogeneous ways. For workers, focusing on linguistic, material or spatial features is a practical issue that has to be handled according to each situation.

\section{Subway signs in Paris}

In this article, we will focus on the case of subway signs, using the results of an ethnographical fieldwork within the Régie Autonome des Transports Parisiens (RATP). In Paris, subway signs became a central issue at the beginning of the 1990s. At this time, a team of specialists (designers, cartographers and architects) was brought together with the aim of reconsidering the whole organization of subway signs. Surveys, field studies and experiments were conducted. This resulted in the creation of a complete way-finding system (a 'signage', signalétique in French) and the writing of a particularly ambitious policy. For the first time, the content, shape, size, colours and emplacement of subway signs were standardized and detailed in extremely precise guidelines. In doing so, the RATP established a real 'writing policy' (Foucault, 1977) that deeply transformed the subway spaces. Because it notably engendered the multiplication of signs within halls, corridors, staircases and platforms, it thus performed a hybrid setting in which 'the distinction between the building and its signs, between the text and the territory, becomes indistinct' (Fuller, 2002: 236). This policy, which was specific to the Parisian subway system, transformed signage into a sociopolitical apparatus that was supposed to make every kind of passenger in every situation aware of the signs' emplacement. It set the basis for a politics of attention in public spaces in which everyone was supposed to be aware of graphical objects that had been placed in the environment (Denis and Pontille, forthcoming).

The placement process was crucial for enacting such an ambitious policy. Since its implantation, a new department, that also deals with the signs' maintenance and repair, has been devoted to this activity. The team is composed of five workers whose previous domains of intervention varied from electricity to mechanics. At the time of our study, they had been in the department for five to eight years. They were not aware of semiotics or any kind of sign theories, but they became real subway sign experts on the job. Because they continually consulted the guidelines on a day-to-day basis, they had a sound knowledge of the details of the policy. Moreover, after walking miles and miles within the Parisian subway system, they acquired a rich experience of sites and situations that was invaluable during the placement work. 


\section{Ethnography of signs placement}

To grasp the pragmatics of placement, we carried out situated observations of workers who daily put up Paris subway signage ${ }^{1}$. We followed the workers, who worked in pairs, during their rounds in subway stations. Our purpose was to reconstitute the spectrum of their activities, to understand the constraints they have to deal with in everyday work and to identify the key resources they use for the signs' placement.

Besides field notes, we took systematic photographs during workers' daily interventions to give an account of different aspects of their work conditions: their main operations, their gestures and the tools they used, the ways they dealt with their surroundings, and so on. Photographs are particularly useful for this kind of study that deals with visible materials (Wagner, 2006); in our case, that meant not only signs but also the handling process of visual artifacts. Taking pictures is a way of precisely documenting the semiotic work that takes place within subway stations, and of emphasizing features that can easily be overlooked when one studies signs, such as the role of materiality or seemingly insignificant gestures (Piette, 1992).

We also paid particular attention to the vocabulary the workers used during their hesitations and discussions about signs and their placement. Such a focus is important in two regards. First, it shows that workers are highly reflexive and that they continuously talk to each other in order to achieve their tasks. Second, it emphasizes the judgement processes that placement work requires. As we will see, to put a board in place cannot be reduced to a mere implementation of placement rules: it is always a decision process with varying degrees of difficulty.

These investigations were helpful in identifying the variety of situations in which workers daily act and in understanding that their work involves heterogeneous ways of treating signs. Furthermore, such an ethnography allows us to emphasize broader political issues. In modern societies, which set up 'information' as a main component of citizenship (Barry, 2001), urban spaces are generally looked upon as functional and inhabitable in themselves. The mobility and orientation of passersby should emerge naturally from architectural buildings, design objects and influx (auto)management. Studying placement processes of signs provides an occasion to 'surface the invisible work' (Star, 1999) that enables visual environments to achieve permanency and efficiency. It is a way for us to shed more light on the material dimensions of the so-called information society and its infrastructures. When signs are essential to the everyday running of subway systems, airports and cities, we assume that the activities of sign workers can be seen as a keystone of public places performation.

\section{Placement process and the emergence of the properties of signs}

Our first observations clearly showed that the workers cannot simply follow directions when they put signs in place. They must make judgements to accomplish the placement process. Of course, in their day-to-day activity, guidelines are useful. They frequently consult them

\footnotetext{
1 This study is part of a larger ethnographic fieldwork about Paris subway signage: conception and design, production and installation, repair and maintenance of signs in the environment. It is also based on interviews of different stakeholders and on the analysis of several documents such as guidelines and reports.
} 
either to confirm a decision or to pick up precise instructions about the way boards have to be 'officially' placed. But these documents all remain on their desks. They do not accompany workers all the way to the sites of their interventions.

When they begin a sequence of work, operators only have at their disposal a work order (WO) that provides a short description of what they have to do: which board needs attention, its location in the station, and the expected operations to restore the situation. We will see that workers never follow these directions automatically: they have to reconcile work orders and the signage policy with the ecology of the local sites. They must find their own way of identifying the proper place for signs within each particular setting. During such an inquiry, they are confronted with numerous dilemmas that involve signs in very distinctive ways.

We will show that to place the subway signs properly, the workers deal with heterogeneous features that emerge in the course of their activities. In doing so, they face what we term practical properties of signs. These properties are practical in the sense that they are not present within signs, but occur during the encounter of objects, bodies and environment (Law and Singleton, 2005). Throughout the placement process, signs are not stabilized entities with univocal features: according to each situation, they oscillate from one quality to another. We will show that, in the case of the Parisian subway signage, signs appear as texts, connected entities, deictics, landmarks, or material objects. Each of these practical properties is connected to specific operations by which workers can achieve placement.

\section{Textuality}

In the course of placement work, subway signs are regularly handled as texts. This is the case, for example, when workers have to replace boards for several reasons: a board whose information is considered as erroneous, a station name incorrectly spelt, information that must be updated, and so on. In such situations, the focus of work is the discursive content of each board: workers look upon signs as intended to be read and the right placement is guided by the need for boards to be legible and relevant.

This textual dimension is an important feature of the placement work since the discursive content does not stop at boards themselves: it is reproduced in the documents that are associated with boards. Each WO contains details about the board to be placed or replaced, and generally indicates its informational content. Partly abbreviated and coded, these descriptions are supposed to help workers to know which board and what place their intervention concerns. Textual dimension of boards is therefore a powerful means of coordination in the actors' network that takes part in the signs placement process. Nevertheless, what is indicated in the document may not be sufficiently explicit, may be only partly reliable in relation to the complete content of the board, or indeed false. Placement work then becomes more difficult, as the following scene shows.

Before entering the station, Robert and Herbert read the WO. It says 'missing board'. A deeper reading of the WO comments section allows Robert to specify the task to be done. In more detail, it says: 'two boards to be removed from the customer service booth window'. The information is completely contradictory: there is no missing board; on the contrary, they have to remove two boards. Once on the scene, Herbert and Robert look at the boards and consult each other. 
Herbert: So, what do we have to take off, finally?

Robert: Two boards have to be removed, so ... this one (pointing out a little red one on the window) and this one (a pink one on the wall, on the right).

Herbert: Are you sure? Because the WO says 'after-sales service' and 'customer service information line 4'.

The text on boards and the text on the WO do not match and Robert and Herbert are overcome by doubt. To clear up the uncertainty, they seek help from the information officer in the customer service booth, who indicates the boards that have to be taken away: the pink one on the wall and another, identical one, on the window. Robert and Herbert remove the two boards.

Even if they seem transparent, textual properties of signs can lose some of their signification in situation. Occasionally, the interaction with another interlocutor can be helpful, such as the verbal precisions from the information officer in this example. The use of oral interrogation is sometimes essential to 'clarify' and 'contextualize' writing, especially in workplaces (Grosjean and Lacoste, 1998). But in most cases, this help is not available. Generally, workers have no other interlocutors and the only way to deal with their doubts is to follow their own points of view.

In these sequences of placement work, the textual properties emerge as the result of the active involvement of workers: they read both the boards and the WO seeking an alignment that has not already been made. They have to find a way of matching information and identifying their precise tasks. Here, since the discursive content is almost exclusively what matters, signs are considered as just vehicles for information. Thus, the purpose of the placement work in this case is to guarantee a proper display for 'messages' that appear on boards.

\section{A network of signs}

In a way-finding system, no sign can stand alone, whether it is in halls, corridors, or on platforms. Each board is designed and arranged in relationship to others. Therefore, for the workers, environment is never solely architectural. During the placement process, they are constantly aware of the numerous signs that are already in place. The network of enamelled boards, stickers and posters constitute a graphical setting they literally inhabit. Both their sound knowledge of the signage policy and the skills they acquired during their continuous displacements within the whole subway system make them experts of such a hybrid environment. This expertise sometimes places them in a position where they go beyond the placement or replacement orders that appear on WOs. Because they never look just at the board that needs attention, but also at the network in which it stands, they may come to take initiatives for displacements, indeed removals, of certain boards.

Nathan has to replace a provisory board in a corner. After finding the sign in question, he hesitates, looking at both left and right corridors and the boards already in place. The WO specifies he has to change the board indicating 'Place de la Chapelle' for a new one because the old one is worn. But after another look at the two boards that frame this one, he decides to remove it instead of placing a new one. He explains aloud: 'This is a provisional board. It's at the proper place but the two others at its left and right are new ones: they are the definitive signs, enamelled. So this one has no 
more reason to be here. I don't have to replace it'. In saying this, he pulls off the provisional sign (Figure 1).

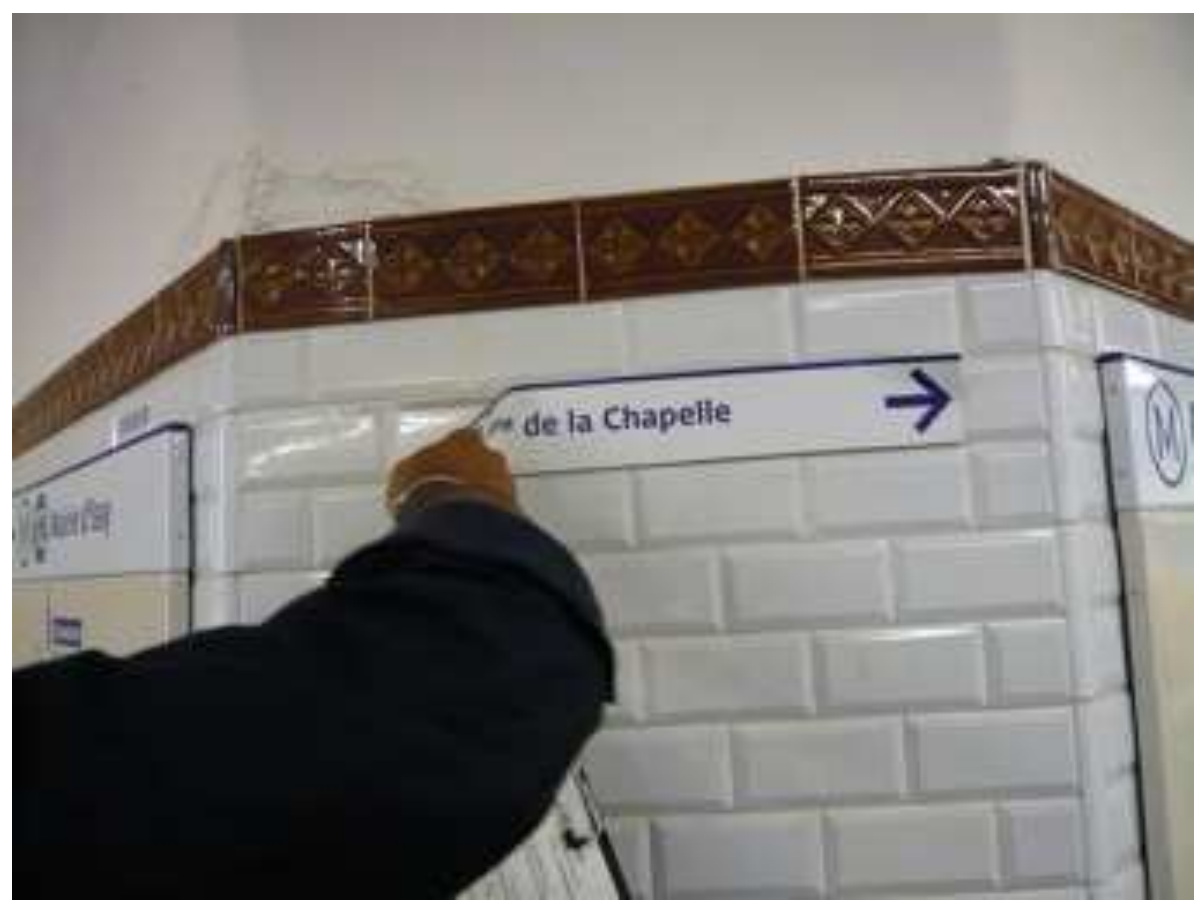

Figure 1. Removing a provisional board. (c Photo: J. Denis and D. Pontille.

A particular place in a subway station is therefore more than just a micro-local occurrence of isolated symbols. This is particularly visible in the following situation where workers initiate a real dynamic relation with the network of signs.

Nathan and Stephan are in a huge station. They try to find the location of a worn board they have to replace. This station consists of three subway lines with a connection to a railway station. There are many platforms and countless corridors. Stephan has the new board in his hand and starts to read the signs he encounters. He tries to find boards that relate to the one he holds. Nathan also looks for clues in the environment (Figure 2). 


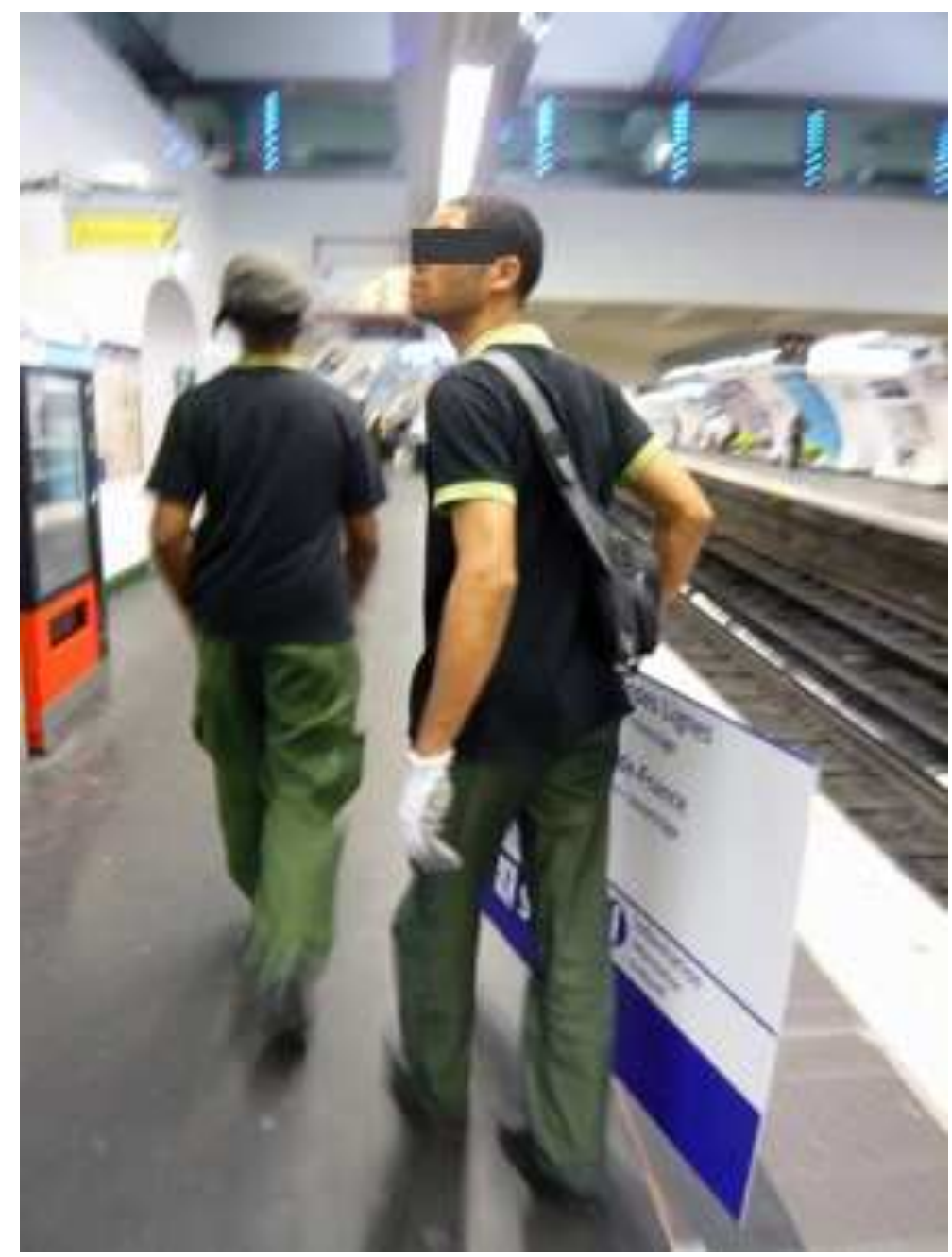

Figure 2. Reading and observing the surrounding signs (C) Photo: J. Denis and D. Pontille.

Stephan finds a track in a corridor. They go down to a platform where signs indicate the same directions as the one they have to put up. Stephan points out a particular one that carries some information in common with the one he holds. He says: 'we just have to follow the others and we will find where one is missing.' After a while, Nathan finds the empty place: across the rails, he points to a board that is exactly the same as Stephan's, but with reversed arrows. The board to be changed must be placed on the other side of this corridor. As they reach the place, Stephan confirms Nathan's intuition.

Networks of signs can be very complex. In large stations, all signs do not refer to each other and a glance is not enough to determine the position of the board to be placed. Workers themselves sometimes have to pace around platforms and corridors in order to follow the trail of signs. In such situations, the environment has to be explored as a graphical ecology where species of signs are tied up with each other and where the equilibrium of places has to be maintained.

\section{Deictics}

During the placement process, signs are also mobilized according to their deictic abilities, that is their 'properties ... of pointing to the world outside of language' (Scollon and Scollon, 2003: 209). Boards are seen by workers as deictics in two different ways. First, deictic 
properties are constituted as resources for action. In relying on them, workers can identify the part of the station where they have to put up a board. The site that the sign points to is thus as much a space for passengers' movements as a workplace for operators.

Nathan and Stephan are on their way to replace a board in a very large station that has to be placed at the top of the entrance stairs. They drive around the square above the station, looking for the right entrance. There are a lot of entrances and they stop the van each time to check if the entrance has the same identification code as the one that figures on the WO. But after they have driven around the entire square and looked at six entrances, they still have not found the right one. Stephan decides to change their tactics. He goes to the back of the van and looks at the board itself. He reads its information and the ones on the WO in order to understand where they have to put up the board (Figure 3).

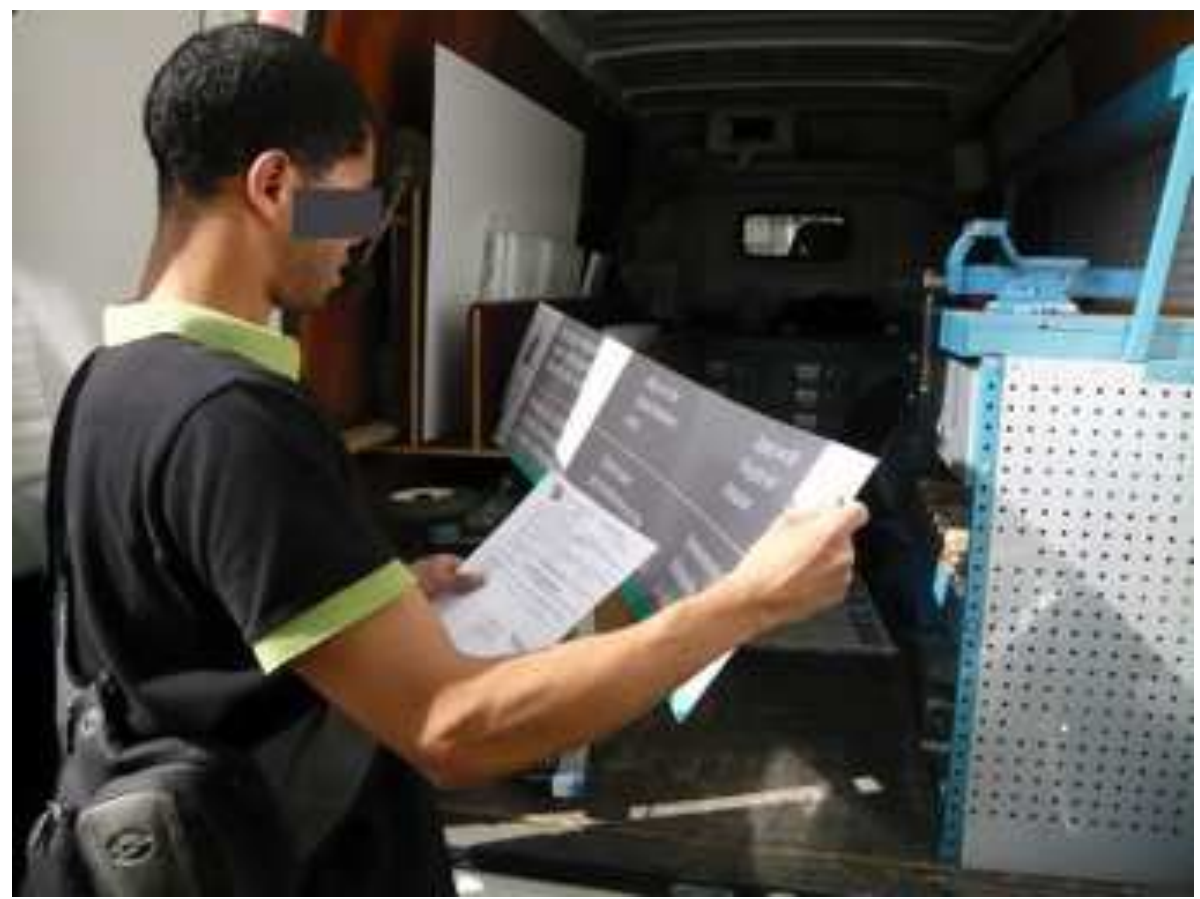

Figure 3. Checking out a board to deduce its location.

(C) Photo: J. Denis and D. Pontille.

The first lines indicate that this access to the station is only for passengers who already have tickets, which means that it is an entrance that provides direct access to the platforms without encountering any ticket booths. The next few lines specify that the nearest ticket booth is located at the main entrance of the inner square. Therefore, there are only two possible solutions for finding the correct place: it has to be one of the entrances on the left but to the right of the main entrance on the inner square. Nathan parks the van in front of the first one and Stephan confirms that the board has to be placed right here.

In this case, deictic properties of signs are considered as stable and easily available. This is why they are clearly a resource for workers' action. But certain situations show that such qualities sometimes have to be enacted. Indexicality is then not present at the beginning of the placement work, but emerges as its result. This is what happens when a fresh site has to be indicated and brand-new boards have to be placed. Deictic properties of the future board are never self-evident, nor do they rely on the informational content or directional symbols 
such as arrows. Workers have to enact them by choosing the position of the board very precisely. This choice sometimes requires the reconstruction of a physical link between the site that has to be indicated and the future board location.

A new museum opened recently in the east of Paris. Its president asked the RATP for its name to be indicated on exit boards on the platforms and in the hall of the nearest station. Paul is sent over there to identify the right place for these boards and to decide which street name will be associated with that of the museum.

In order to make his decision, he first looks around the outside of the station and tries to identify the right exit. On his way to one of the three possible exits, he mobilizes several elements to confirm his choice. First, he looks for the museum building. Once it is in sight, he looks again at the other exits. His choice seems to be made: one of the exits is clearly further away and the other one would involve crossing a wide avenue.

Then he goes down to the station and walks back along the way that will be indicated by the exit boards: from the hall to the platform. In doing so, he can identify the boards to be replaced by the new ones that will include the museum name.

From his observations, and then through his own movements, Paul experiences the potential deictic properties of the future boards. He has put to the test the deictic relation in covering the space between the indicated site and the future deictics' location. But this first move is not sufficient for his choice to be definitive. Paul is still wondering if the name of the street he chose is the right one. To strengthen his choice, he mobilized other resources.

In the station, Paul carefully reads the street names on existing boards. He pays particular attention to the ones that point to the exit he chose. The boards that will carry the name of the new museum must refer to a sole street. To check this, he walks again as far the exit. Outside, another device allows him to confirm that the places for the future boards and street name are the right ones: the neighbourhood map. He reads it carefully, spots the museum on it and the junction where his chosen exit is sited (Figure 4).

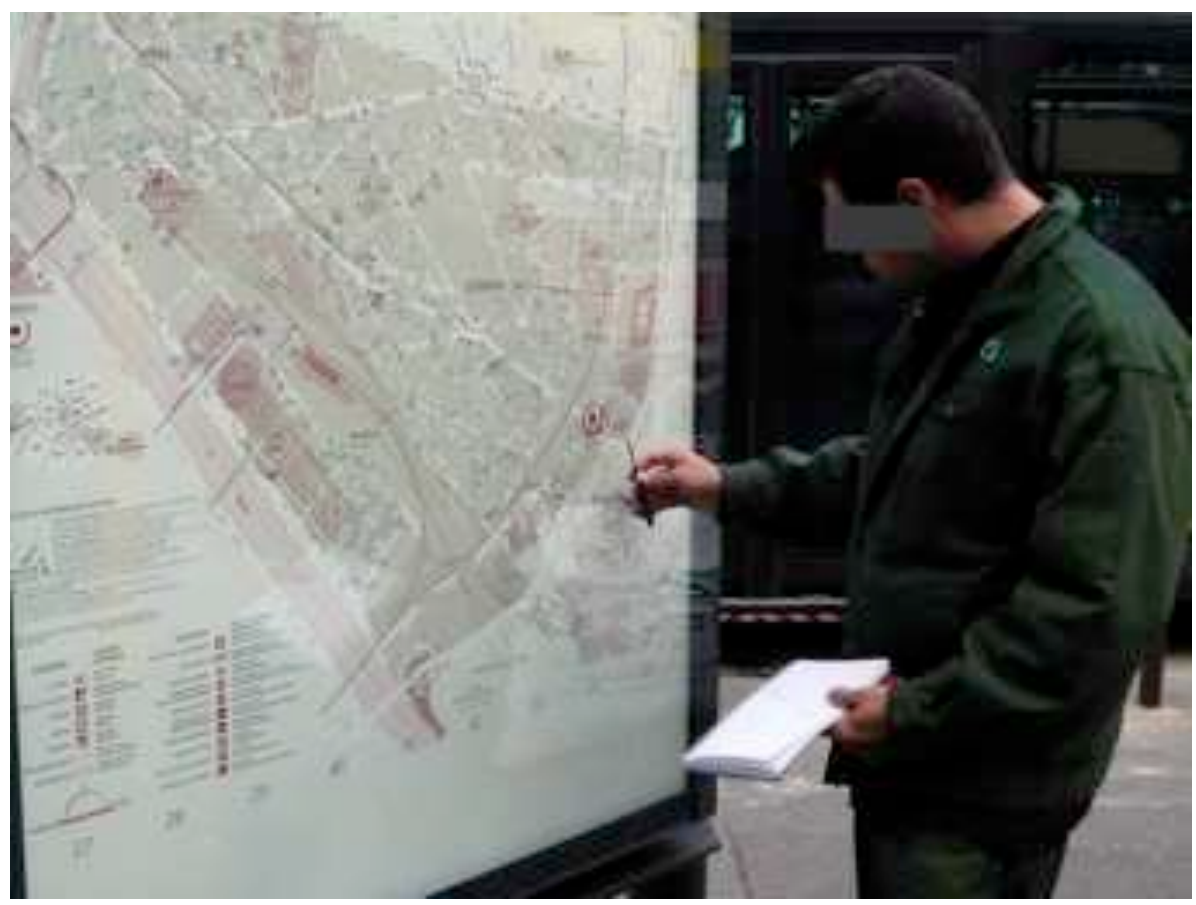

Figure 4. Reading a neighborhood map to confirm a choice. ( ) Photo: J. Denis and D. Pontille. 
Finally, he tries to read the street name plates on the other side of the avenue to be sure there is no possible confusion. Once all crosschecking has been done, he confirms in his notebook the location of each future board and the street name to be associated with that of the museum.

The other deictics such as the neighborhood map offer important resources for corroborating the emplacement choice. Actually, this case clearly shows that they also constitute specific constraints. For the deictic properties of a future board to be enacted, workers cannot simply place the sign in the right place and ignore other way-finding artifacts. This could create situations of cognitive conflicts where indications on different signs are not adjusted to each other, and may be completely contradictory. Here, the awareness of the connection between signs goes beyond halls, corridors, stations and their signage. A larger network has to be performed: heterogeneous deictics have to be aligned with others ${ }^{2}$.

These cases show that the capacity for signs to point to specific sites is the result of embodied practices. Deictic properties have to be enacted. Movement here is essential. The stability of a board, its installation in a fixed place, is the outcome of the circulation of Paul's body. He builds the deictic thread from the signs within the station to the site of the museum with his feet, by pacing up and down spaces. Thus, it is by his own movements that he can successfully form a network from a set of heterogeneous signs (various indexes of the station, the neighborhood map, street nameplates, etc.). In doing so, we could say that Paul carries out the correspondence between the world and the inscriptions that represent it, just as some scientists do (Latour, 1995). However, as Fuller (2002) put it, signage is not a matter of representation: it deals with the ordering of the environment and its users. By walking back and forth, Paul put to the test, step by step, the link that names and arrows on the board forge between places.

\section{Landmarks}

A fourth way consists of the consideration of the signs as direct supporting resources for action. In this case, emplacement assembles both visual and pragmatic properties. The 'push' sticker that has to be stuck on certain doors (Figure 5) is a typical example of such a situation. Admittedly, it has to be seen but, most of all, its emplacement has to precisely indicate where one has to put one's hand to open the door properly.

2 The performation of such a large network is important because subway systems are not "nonplaces" (Augé, 1995): they are tightly tied to the city. 


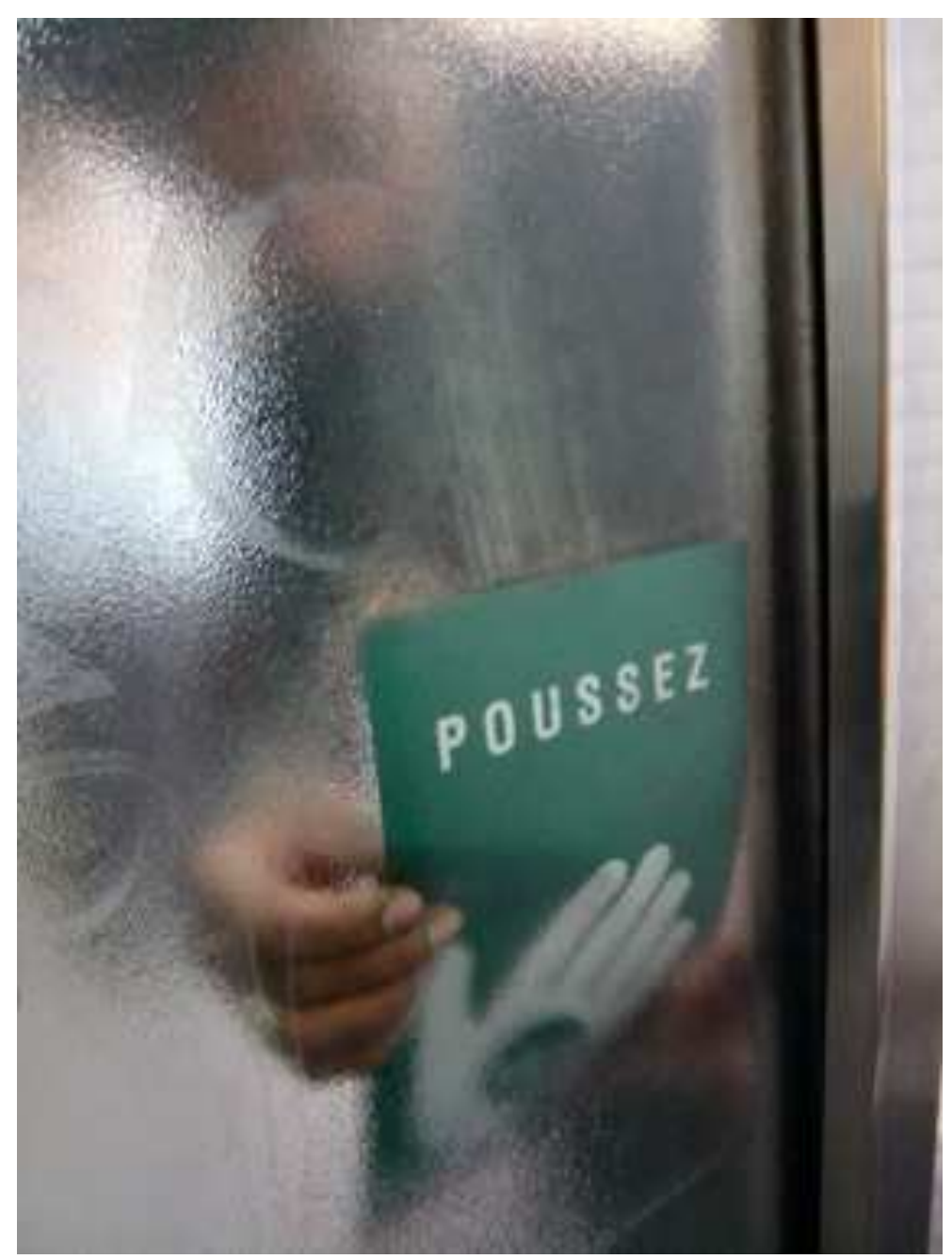

Figure 5. Putting up a sticker. (c) Photo: J. Denis and D. Pontille.

Here, the sign is conceived of as a landmark. From this point of view, the crucial point in the placement work is its ability to become a resource for action and the availability of the sign matters much more than its legibility. It has to be salient within the environment in order to carry an almost transparent perception/action process, in the same way that some cognitive systems rely on perceptive tasks (Hutchins, 1995).

To enact this property is not too difficult for the workers when it is about signs that involve the hand's movement. It is more complex to assess the way more distant boards can catch the eye.

Herbert and Leonard have just finished putting up a board that indicates the name of the station on a platform wall. Leonard steps back, and looks at the result of their work. He glances at the entire platform, estimating its length, and says, doubtfully: 'we should have provided two boards! The passengers in the last carriage cannot see anything. If I was there I could definitely not see it [the board].' Here, the emplacement of the board they just put up is not at stake. It is the need for an additional one that is questioned. In order to check its relevance, they decide to wait for the next train. When it comes, they observe the passengers' faces and glances. Some of them are obviously looking for the name of the station. They do not immediately find the board. After this test, Herbert and Leonard agree to order another board for the end of the platform. 
When they enact signs as landmarks, placement workers deal with action. And since the experiment is carried out on the spot, they have to make their own way of putting the board's availability to the test. First, they take the place of passengers who get out of the carriage. In so doing, they assess the qualities of the board with their own eyes: they perform an 'embodied representation' of users (Barrey et al., 2000; Denis, 2008), grounded in their ordinary competencies as passengers. Second, they take advantage of the direct presence of users within their workplace: to complete the first experiment, they carry out a quick observation of passengers' attitudes towards the signs. Users are within easy reach, moving in their 'natural' environment. By examining their movements, workers can assess the landmarks-to-be in their own environment.

\section{Materiality}

Finally, a simple look at the subway signs during work processes allows the understanding of a very simple fact: signs that may be considered as texts, connected entities, deictics or landmarks are also objects. Installation is made by handling activities: workers have to carry boards, put them up on walls, take them down, and so on (Figure 6). Dealing with materiality is thus a crucial way for workers to treat subway signs.

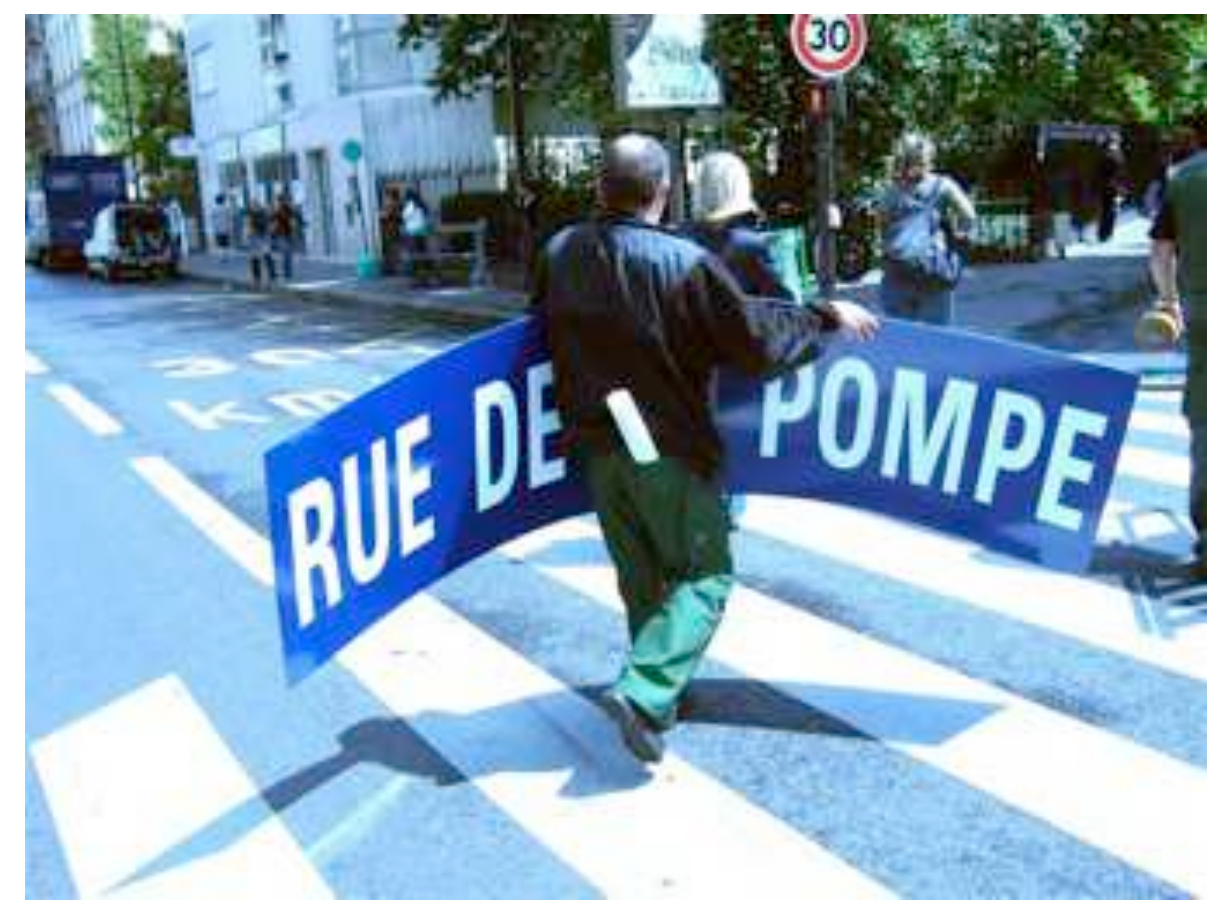

Figure 6. Carrying a board. @ Photo: J. Denis and D. Pontille.

In carrying out all these operations, workers do not pay any attention to the discursive content of the board, nor to its graphical composition. All that matters is the efficiency of hanging, the straight alignment of the board with the tiles and its cleanness. When workers treat the subway signs as objects, their activity is oriented towards a unique purpose: to stabilize boards in the physical environment.

Nathan and Stephan have to put up a new signboard to replace the older one that broke when it fell off the wall. They first have to put up new metal brackets, for which they drilled holes beforehand. Then they measure both board and brackets, and 
scribble a few marks on the wall. They use the tiles as a guide to make sure the new board will be positioned straight. For these operations they use two different drills, glue cement, a pen, a measuring tape, a screwdriver, plugs and screws (Figure 7). Once the board is put up on the wall, Stephan carefully wipes it and says: 'Here it is, a brand new sign.'

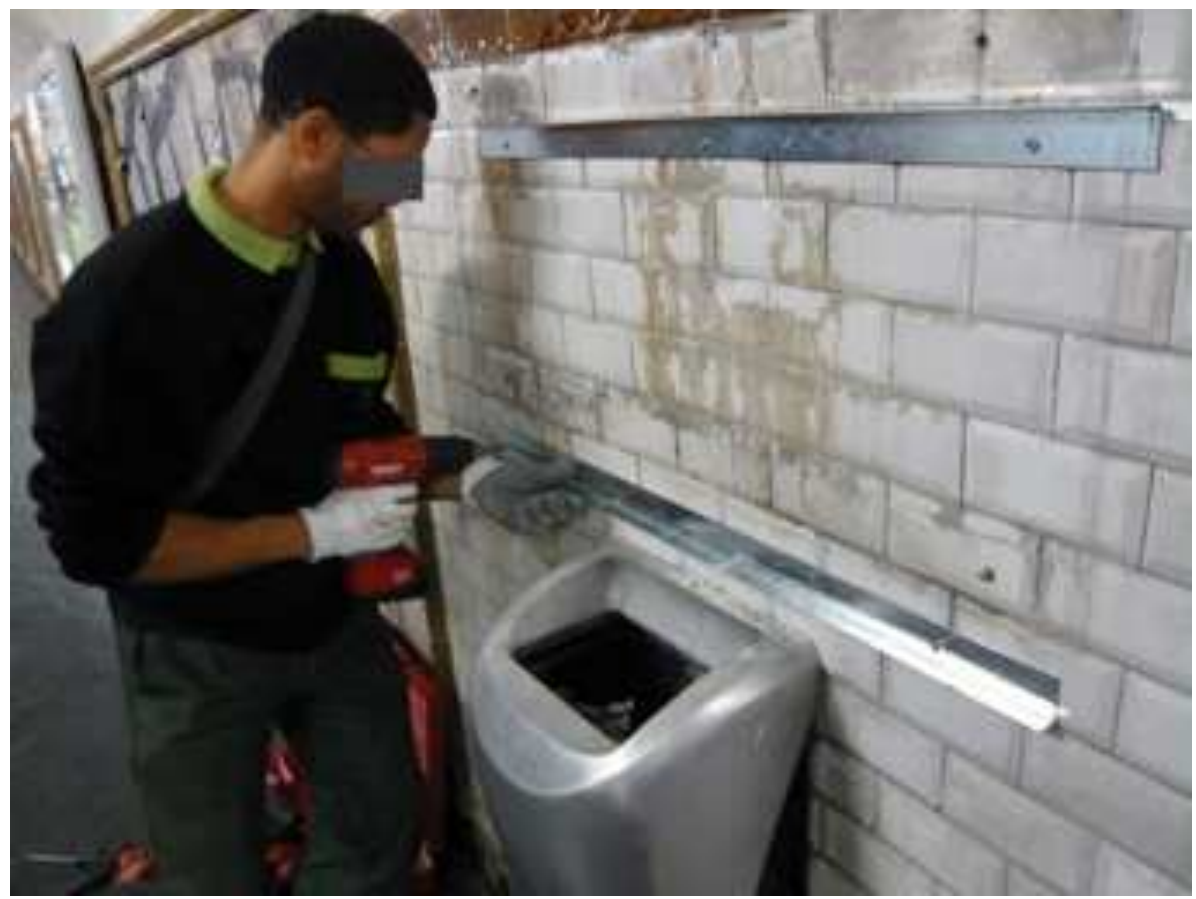

Figure 7. Drilling. (c) Photo: J. Denis and D. Pontille.

Material properties of signs thus raise particular issues that we call 'ecological': dealing with it implies a whole infrastructure of tools, devices, materials (concrete, plaster, tiles) and energy supply. For instance, during this sequence of activity, Nathan and Stephan had to pause to recharge the battery of the second drill. Operators are then confronted with the interdependence of technical networks. Therefore, during placement work, as in repair and maintenance situations (Graham and Thrift, 2007), workers have to deal with the strengths and limitations that make up the material order of inherited infrastructures (such as the electricity network).

Material issues occur in another way during placement work: not as an outcome of work but as a constraint. In these cases, boards are grasped as objects 'present-at-hand' whose material properties create difficulties.

Nathan and Stephan have to change a board in order to update its information. The amount of handling they have to do for this seemingly simple operation is surprising. Sixteen small screws have to be removed from the metal frame in order to take down the broken board (Figure 8). Once it is done, they put up the new plaque very carefully: a false move could damage it. Then they screw back the frame before hanging it up on the ceiling. 


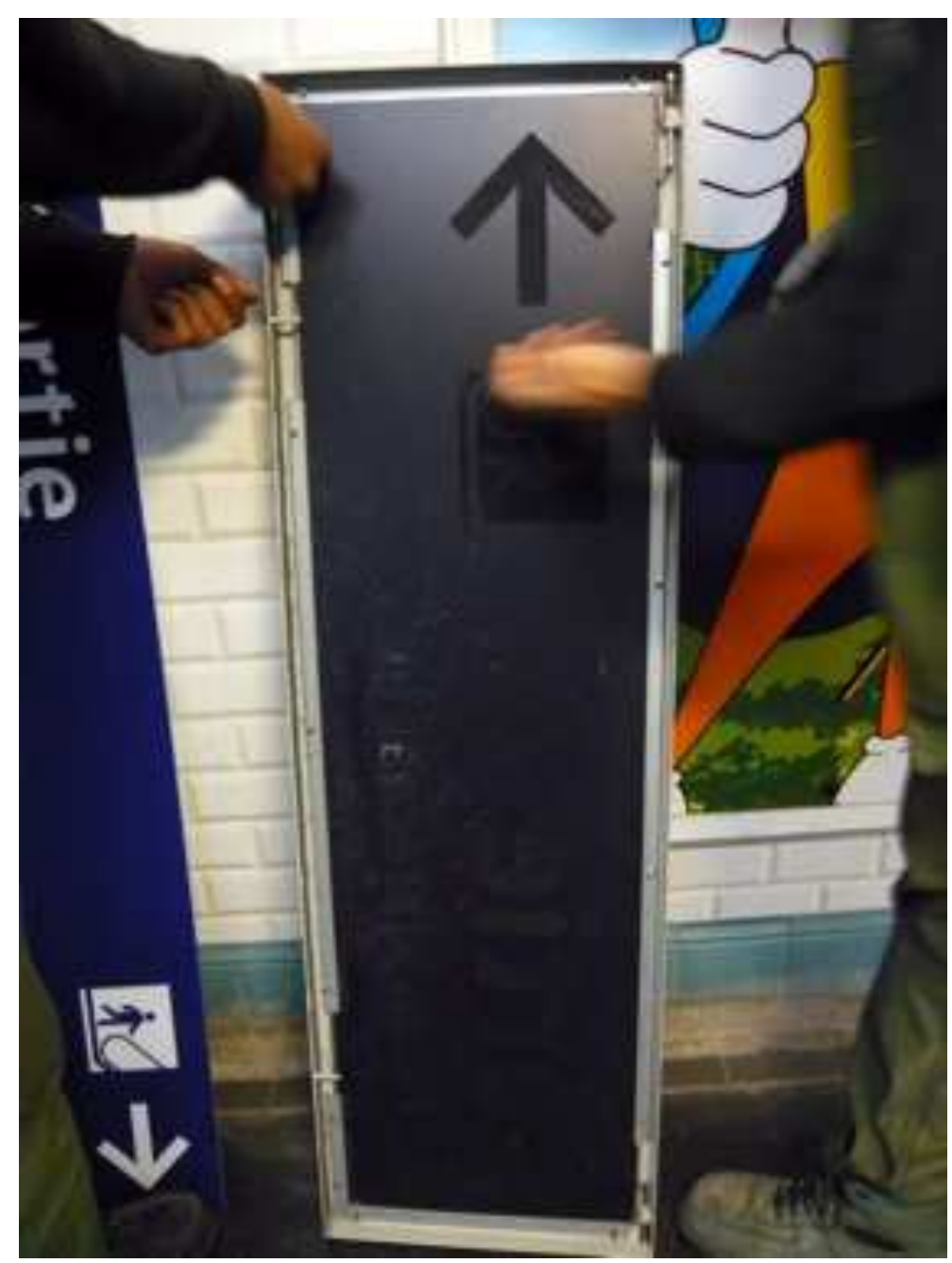

Figure 8. Removing screws. ( Photo: J. Denis and D. Pontille.

Workers' practices depend largely on designers and manufacturers who do not necessarily take their activities into account when they make brackets or frames. When they consider boards as objects, workers are confronted with a material assemblage that is the result of activities prior to their own. In these cases, they handle signs as stabilized entities whose materiality is a particularly resistant feature in the completion of their work.

Therefore, there are two ways that material properties emerge during placement work. On the one hand, materiality is an outcome of placement work process, it appears as the stabilized result of the workers' distributed activity. On the other hand, materiality is a preexisting component of the situation, the sign that there is already a stabilized object that may be particularly resistant to the workers' interventions. The main challenge for workers when making placements is to face up to the constraints of the material features assembled in a sign in order to enact the ones required by its proper placement.

\section{The articulation of the properties of signs}

For our purposes, we have successively isolated several ways of treating signs. Each of them was illustrated by different micro-local empirical scenes, where specific qualities emerge. Such a perspective is particularly helpful for shedding light on the multiplicity of signs' practical properties that occur throughout placement work. However, it does not reflect 
the entire process that encompasses the placement of subway signs. In most cases, the same sign can oscillate from one quality to another. The main issue for workers is then to articulate these various properties during the same intervention. In order to understand this articulation process, it is necessary to follow workers in a longer sequence of action. This is the aim of this last section.

During our inquiry, a new directive was issued by the security department: from that time on, emergency exits had to be indicated by a set of new signs and to be marked out from platforms to streets. Herbert and Leonard were sent to a station after the security staff had pointed out different emplacements for these signs. Their task consisted of confirming or rejecting these choices.

For the observer, the situation seems clear. From a geosemiotic perspective, emergency signs are the archetype of deictics (Scollon and Scollon, 2003). When validating or rejecting the security staff's propositions, there is no doubt that workers will mainly assess emplacements according to signs' deictic properties. The right place will be the one that allows the sign to effectively point to an exit. However, as soon as Herbert and Leonard go down to the station's hall and check for the first proposition, things get more complicated.

The security department suggested putting up an emergency sign on a large existing board. Straightaway Leonard rejects this choice. He explains that the board already displays the names of two exits, several figures and the names of lines that point to connections to subway lines and bus routes. Here, Leonard's refusal is based on the discursive content of the sign: in his opinion, the board will display too much information if one adds an emergency sticker. Furthermore, he underlines the possible contradiction of the texts: each word, figure and icon on this board is devoted to the day-to-day normal flux, an emergency sign would strongly interfere with them.

But the presence of emergency signs in the station is compulsory. Herbert and Leonard then have to come up with another solution to finding a place for this first sign. In other words, they have to find a position for it within the internal network of signs, without weakening its consistency. Their first movement is to walk through the hall and to act as passengers. In so doing, they treat the future signs as landmarks. They adopt different points of view in the corridor; they walk all around the entrance hall and try to discover which place would make the signs most salient for passengers.

For instance, in front of the revolving doors, Leonard says: 'Here riders can't see the stairs that lead to the exit. So we could put stickers on the doors ...' Herbert does not say anything, but he seems doubtful. Leonard continues: 'Or we could put a sticker on the window of the customer service booth. It is not great, but that is an option.'

Here, workers rely on passengers' ordinary competencies to judge where pertinent and visible information should be placed. However, some new difficulties make them adopt another viewpoint. As they consider the possibility of putting up a new board dedicated to the emergency sign, materiality suddenly appears as a crucial issue.

Herbert and Leonard are back in front of the existing board. Leonard looks up: 'The concrete ceiling can withstand another board hanging on a chain. It could be a solution. The board will be visible whatever the circumstances since the light is sufficiently intense.' But Herbert notices: 'The gap between the ceiling and passengers' heads is 
too short. Some tall passengers may hurt themselves.' Leonard turns around, looks up again and adds right away: 'and the board would be hidden by this video camera. Besides it may hide information given on the existing board' (Figure 9).

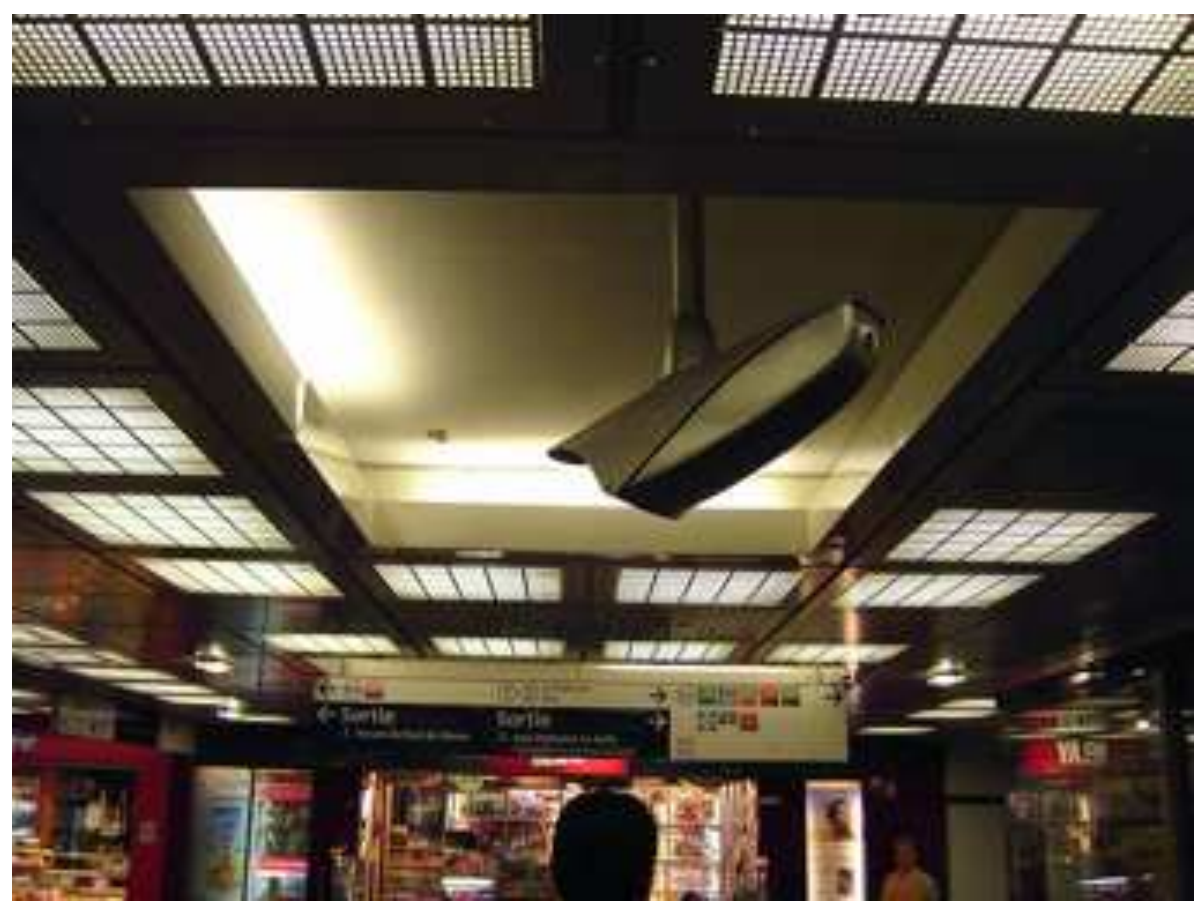

Figure 9. The board, among other objects. ( ) Photo: J. Denis and D. Pontille.

As soon as workers take into account the material property of signs, they have to deal with several other elements that are present in the environment. No piece of information must weaken, disrupt or refute another one, nor can a sticker or a board hide an existing one. Furthermore, in this example, a whole ecology of entities emerges as pertinent: lights, video camera, pillars and passengers themselves play a role in the decision process.

This case shows how workers can find themselves in a particularly challenging situation during the placement process. They try a lot of various options, assess and discuss potential means, and hesitate for a long time before coming to a final decision. The latter requires the articulation of all signs' properties that occurred during their inquiry. In this example, Herbert and Leonard finally choose to put up stickers on the revolving doors. Such a solution sheds a new light on the placement process: its result represents the identification of an available emplacement. And availability is a very complex thing. First, the place for the future sign has to be graphically available: it should not already display any other inscriptions. By choosing the back of revolving doors for 'exit' stickers, workers avoid any risk of disrupting the surrounding graphical order. Second, the place must be materially available: the stickers will not hamper passengers during their displacements. Third, the place must be pragmatically available. Ordinarily, the back of revolving doors is inoperative. Exit stickers will not come into conflict with other forms of action by pointing to a new possible exit in case of emergency. In such an operation, the doors are themselves transformed. Initially devoted to prevent passengers from entering without a ticket, the back of the doors is now used as a security apparatus. 


\section{Conclusion}

The placement process relies on workers' activities that cannot simply consist of following directions. Almost each intervention brings them to the same crucial question: where is the right place for this sign? To answer this question, workers carry out a meticulous exploration of the environment in which they strive to reconcile the signage policy with the ecology of the local sites. In doing so, we showed that they are not discovering an emplacement that was waiting for a sign: they enact an available place, mobilizing numerous embodied practices (such as walking around the station or adopting passengers' positions). During such an inquiry, signs themselves are not treated as stabilized entities. They oscillate from one quality to another as the placement process goes on. Thus, in enacting the right place, operators face the multiplicity of what we termed the practical properties of signs. We showed that, according to the situation, the subway signs occurred as texts, connected entities, deictics, landmarks or material objects. These properties are not already there, within signs, but arise out of the action and have to be taken into account to achieve the placement work. To put subway signs in the 'right' place, these emerging properties have to be prioritized and articulated. Thus, this is not only the environment, but also signs themselves that are enacted and stabilized during the placement process.

To conclude, we would like to tackle the question of the possible generalization of this ethnography of placement work. How could such research be relevant for studying other subway systems or even the placement of other kinds of graphical objects in public spaces? Since it offers a way to focus on the backstage view of 'signs in place', we think that the analysis of the practical properties of signs that occurs during the placement work could be useful, to a larger extent, in geosemiotics studies. However, such research has to be mobilized with certain precautions.

First, one has to keep in mind that placement work is not a generic activity. Placing signs is always accomplished in a specific environment and within a larger sociopolitical setting. For instance, we saw that in Paris, the subway signage policy is a very ambitious one. It was conceived as an important component of a strong process of ordering, for the sake of which the amount of signs within the environment is extremely large and the whole way-finding system is highly standardized. One cannot understand the complexity of the placement work that we described without taking into account this policy: it is present within workers' activity through the guidelines that lie on their desks and the work orders that they hold in their hands when entering a station.

In other terms, the generalization of our placement work study could not just rely on the collection of observations of micro-tasks in other settings. It would require a broader view of workers' activity that would allow researchers to be aware of the political dimension that accompanies the placement process in the form of normative documents and situated directions. The organization of work itself is also important: placement does not always appear as an official dedicated activity. In a comparative setting, such a perspective would offer a useful means for a full understanding of the culturally specific features of each situation, without referring to mysterious impalpable social forces.

Second, one has to be aware that the analysis of placement work may lead to an inadequate impression of stability. Once an available place has been identified and the sign has been 
fixed to a wall, one could easily think that the process of ordering is achieved, and then begin to focus on other parts of it (for instance, the situated uses of boards and stickers). As demonstrated by some of the situations described in this article, such a view would be a complete misunderstanding. Social order is a matter of continuous performation, and in respect of its other domains (Graham and Thrift, 2007), graphical order has to be maintained from day to day. A sign is never placed once and for all. It may be damaged, contain obsolete information, or simply get worn. The sites that it points to may also change. The activity of placement is thus always tightly linked to the activities of repair and maintenance. The study of the latter would provide a decisive complement for the foray we made into the backstage view of 'signs in place'.

\section{Acknowledgements}

This research is part of a collective project entitled 'Ecologies and Politics of Writing' (Département Sciences Économiques et Sociales, LTCI (UMR 5141) CNRS, TELECOM ParisTech and Anthropology of Writing Team, IIAC (UMR 8177) CNRS-EHESS) and supported by the Agence Nationale de la Recherche, Grant n ${ }^{\circ}$ NT05-1_42082. We would like to acknowledge the staff of the Régie Autonome des Transports Parisiens (RATP) for their active cooperation in this study. We are also grateful to Delphine Burali for her support in translation, and to two anonymous referees for their helpful comments on a previous version of this paper. 


\section{References}

Augé, M. (1995) Non-Places: Introduction to an Anthropology of Supermodernity. London: Verso.

Barrey, S., Cochoy, F. and Dubuisson-Quellier, S. (2000) 'Designer, Packager, Merchandiser: Trois professionnels pour une même scène marchande', Sociologie du travail 42(3): 457-82.

Barry, A. (2001) Political Machines: Governing a Technological Society. New York: Athlone Press.

Denis, J. (2008) 'Projeter le marché. Les saisies du public dans un service de production télévisuelle', Revue française de socio-économie 1(2): 161-80.

Denis, J. and Pontille, D. (forthcoming) 'The Graphical Performation of a Public Space: Subway Signage in Paris', in G. Sonda et al. (eds) Urban Plots, Organizing Cities. Farnham: Ashgate.

Foucault, M. (1977) Discipline and Punish. Harmondsworth: Penguin.

Fuller, G. (2002) 'The Arrow-Directional Semiotics: Wayfinding in Transit', Social Semiotics 12(3): 231-244.

Graham, S. and Thrift, N. (2007) 'Out of Order: Understanding Repair and Maintenance', Theory, Culture \& Society 24(3): 1-25.

Grosjean, M. and Lacoste, M. (1998) 'L'oral et l'écrit dans les communications de travail ou les illusions du "tout écrit"', Sociologie du travail XL(4): 439-65.

Hutchins, E. (1995) 'How a Cockpit Remembers Its Speeds', Cognitive Science 19: 265-88.

Jenks, C. (ed.) (1995) Visual Culture. London: Routledge.

Latour, B. (1995) 'The "Pedofil" of Boa-Vista: A Photo-Philosophical Montage', Common Knowledge 4(1): 145-87.

Latour, B. and Hermant, É. (1998) Paris ville invisible. Paris: La Découverte.

Law, J. and Singleton, V. (2005) 'Object Lessons', Organization 12(3): 331-55.

Petrucci, A. (1993) Public Lettering. Script, Power, and Culture. Chicago: University of Chicago Press.

Piette, A. (1992) Le mode mineur de la réalité. Paradoxes et photographies en anthropologie. Louvain-la-Neuve: Peeters.

Scollon, R. and Scollon, S.W. (2003) Discourses in Place:. Language in the Material World. London: Routledge.

Star, S.L. (1999) 'The Ethnography of Infrastructure', American Behavioural Scientist 43(3): 377-91.

Van Leeuwen, T. and Jewitt C. (eds) (2001) Handbook of Visual Analysis. London: Sage.

Wagner, J. (2006) 'Visible Materials, Visualised Theory and Images of Social Research', Visual Studies 21(1): 55-69. 